\title{
Surgical tracheotomy in COVID-19 patients: an Italian single centre experience
}

\author{
Roberto Briatore ${ }^{1} \cdot$ Federico Aprile ${ }^{1}$ (D) Agostino Roasio ${ }^{2} \cdot$ Alessandro Bianchi $^{2} \cdot$ Stefano Bosso $^{2} \cdot$ Livio Carmino $^{2}$. \\ Laura Lorenzelli $^{2} \cdot$ Martina Scanu $^{2} \cdot$ Mattia Zanin $^{2} \cdot$ Giuseppina Bosso $^{3} \cdot$ Vincenzo Torchia $^{3} \cdot$ Paolo Pisani $^{1}$
}

Received: 27 December 2020 / Accepted: 9 February 2021 / Published online: 22 February 2021

(c) The Author(s), under exclusive licence to Springer-Verlag GmbH, DE part of Springer Nature 2021

\begin{abstract}
Purpose Coronavirus infection disease 2019 (COVID-19) causes in 10\% of patients a severe respiratory distress syndrome managed with invasive mechanical ventilation (IMV), sometimes difficult to wean. The role of tracheotomy is debated for the possible risks for patients and staff. We are going to describe here our experience with surgical tracheotomy in COVID19 positive patients.

Methods We enrolled all intensive care unit (ICU) patients requiring longer than 10 days of IMV. Demographic, clinical, respiratory, complications, and outcomes data were collected, in a particular length of weaning from sedation and IMV, in-ICU and in-hospital mortality rate. All healthcare operators involved were tested for SARS-CoV2 by pharyngeal swab and blood test (antibody test).

Results 13 out of 68 ICU patients $(19.1 \%)$ underwent surgical tracheotomy after a median intubation period of 14 days. The mean age was 60 (56-65) years. 85\% were male patients. Postoperative mild bleeding was seen in 30.7\%, pneumothorax in 7.7\%. Mean weaning from sedation required 3 days, 19 days from IMV. In-ICU and in-hospital COVID-infection-related mortality was $23.1 \%$ and $30.7 \%$, respectively. None of the healthcare operators was found SARS-CoV2 positive during the period of the study.

Conclusions In COVID-19 pandemic surgical tracheotomy enables to wean from sedation and subsequently from IMV in a safe way for both patients and personnel.
\end{abstract}

Keywords Coronavirus infection disease $\cdot$ Covid-19 $\cdot$ SARS-CoV2 $\cdot$ Tracheotomy $\cdot$ Respiratory distress syndrome

\section{Introduction}

Coronavirus infection disease 2019 (COVID-19), declared a pandemic by World Health Organization, has been spreading around the world impacting deeply hospital care at different levels [1]. During the first phase of pandemic, Italy was one of the hardest hit countries for the number of people infected. Piedmont, in Northern Italy, recorded over 30,000 affected people within 3 months [2].

Federico Aprile

federico.aprile89@gmail.com

1 Department of Otorhinolaryngology, "Cardinal Massaia" Hospital, Corso Dante Alighieri, 202, 14100 Asti, AT, Italy

2 Department of Anesthesia and Intensive Care, "Cardinal Massaia” Hospital, Asti, Italy

3 Operating Room Service, "Cardinal Massaia" Hospital, Asti, Italy
Novel coronavirus (SARS-COV2) caused acute respiratory distress syndrome characterized by a wide range of clinical presentations which, in nearly $12 \%$ of subjects, required intensive care unit (ICU) recovery [3]. Patients admitted to ICU with severe respiratory syndrome were treated in over $70 \%$ of cases with oro-tracheal intubation and subsequent invasive mechanical ventilation [4]. Furthermore, critically ill patients frequently suffered from severe muscle weakness due to prolonged immobilization and use of profound neuromuscular blockage. Thick airway secretions usually found in these patients made airway patency difficult to maintain [5]. All of these reasons explain the need for prolonged and difficult weaning from invasive mechanical ventilation in such patients, with a high risk of developing complications like hospital infections, thrombosis or even prolonged swallowing impairment with silent aspiration [6].

Tracheotomy, widely used in critical care, was performed in $8-13 \%$ of all critically ill patients before the COVID-19 
pandemic [7]. Tracheotomy is commonly considered a cornerstone in critical care to ease weaning from invasive mechanical ventilation due to reduction of work of breathing, less use of sedative, and more collaborative patient. However, its use in COVID-19 patients is still debated and not unanimously recommended due to potential high risk for both patients and healthcare operators. Airway manipulation and loss of positive airway pressure during tracheotomy may be detrimental especially in the case of critical hypoxia as seen in most of these patients. Then, SARS-CoV-2 virus, transmitted through aerosol generation and contact with contaminated surfaces, is associated with high droplet and particle generation, placing health care providers at increased risk for transmission of respiratory viral infections.

Despite protocols and guidelines written by international groups, some issues concerning tracheotomy in COVID19 pneumonia are still debated, in particular related to the choice of the right patient, timing, techniques and ventilator setting [8-12].

Up to date, few experiences about tracheotomy in COVID-19 people are reported [13-18].

The aim of our study was to share our single-center experience on surgical tracheotomy in patients with COVID19 , outlining its safety for both patients and healthcare personnel.

\section{Materials and methods}

\section{Type of the study}

Our retrospective observational study was realized in a second level Italian hospital (Cardinal Massaia Hospital-Asti, Italy).

\section{Patients enrolled}

During COVID-19 outbreak, 10-beds ICU was expanded to 30 beds and converted into negative pressure environment. We retrieved data regarding all COVID-19 positive patients admitted in ICU from March 1th to May 15th 2020 requiring tracheotomy.

In our experience the criteria to practice tracheotomy were:

- an invasive mechanical ventilation longer than 10 days

- acute respiratory distress syndrome ventilated with any positive end-expiratory pressure (PEEP) and fraction of inspired oxygen $\left(\mathrm{FiO}_{2}\right)$

- hemodynamic stability.

\section{Technical and safety aspects}

All surgical tracheotomies were performed by an expert surgical team composed by two skilled head and neck surgeons, an anesthesiologist encharged of tracheal tube and mechanical ventilation management, a scrub nurse, an assistant nurse and a nurse to support the anesthesiologist. The procedure was realized in a negative pressurized operating room to reduce the risk of viral spreading [19]. All operators followed WHO guidelines for aerosol-generating procedures performed on COVID-19 patients [20]. Before getting dressed, bracelets and other jewelry were removed for surgical scrubbing. Then each operator wore a protective cap and shoe covers, FFP3 or N95 mask, safety goggles or face shield, double gowns and double nitrile gloves. All operators in the operating room were protected (Fig. 1).

All patients were monitored as usual in our operating room (oxygen saturation, end tidal $\mathrm{CO}_{2}$, blood pressure, and electrocardiography).

The surgical technique did not differ from the original one but some crucial points must be underlined:

- monopolar electric scalpels were avoided to prevent aerosol generation.

- before opening the trachea it is mandatory to have the best possible oxygenation $\left(\mathrm{O}_{2} 100 \%\right.$ for $\left.3 \mathrm{~min}\right)$ and deep muscle paralysis (to avoid couching);

- the ventilator is turned off immediately before tracheal incision to avoid the aerosol generation of blood or tracheal secretion;

- just before the surgical incision of the trachea, the tracheal tube is pushed up as much as possible to avoid cuff breach;

- the trachea is opened between the second and third ring by a scalpel to reduce the risk of airway fire due to high oxygen concentration;

- when the airway is open, any electrosurgical device is no longer used to avoid the risk of aerosol generation;

- the removal of the tracheal tube is the most hazardous step of all the procedure due to the risk of infection spread. The ventilator is completely stopped, tracheal tube is lifted avoiding complete extubation, then nonfenestrated tracheal cannula is inserted in the lumen. The cannula cuff is promptly inflated at an appropriate pressure. Heat and moisture exchanger filter closes the circuit. Only at this point ventilator is resumed. The correct tracheal tube position is checked with end-tidal $\mathrm{CO}_{2}$, avoiding thoracic auscultation to not contaminate the stethoscope. At this point, the tracheal tube is completely removed.

- the anterior trachea wall should be sutured to the skin to facilitate insertion and postoperative management. 
Fig. 1 Operating theater: tracheotomy in a COVID-19 patient

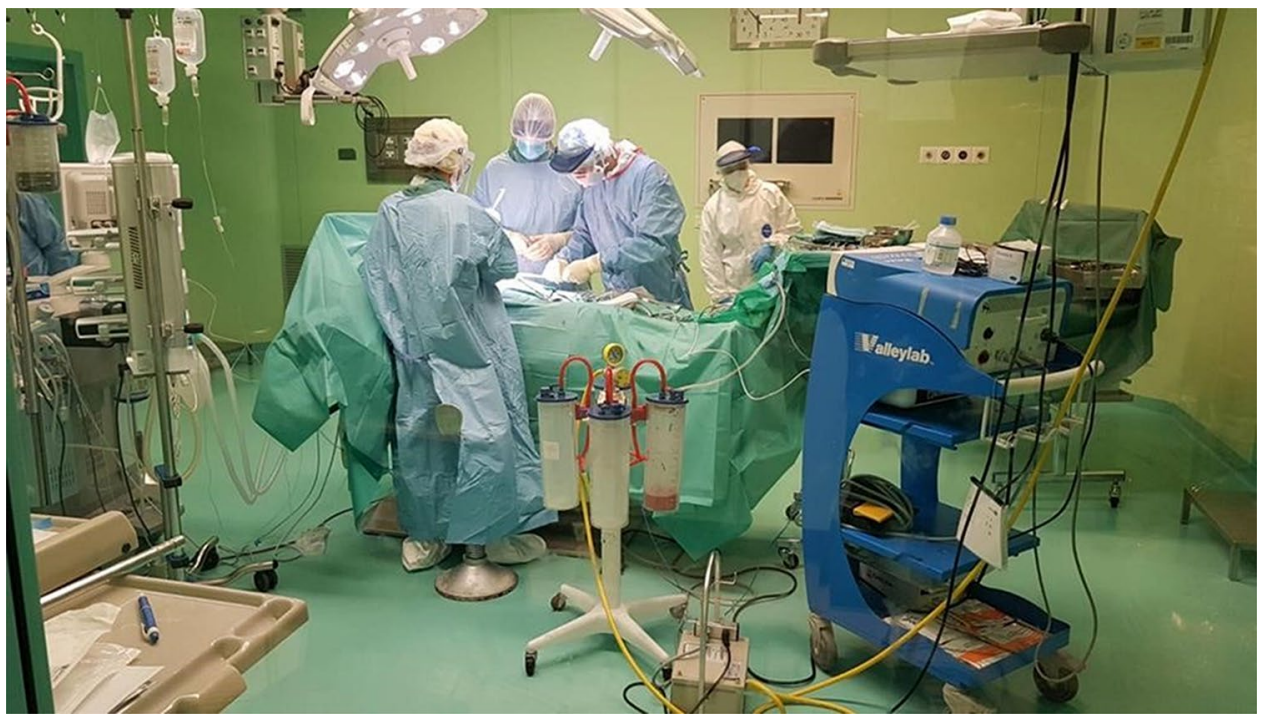

\section{Data collected}

The data were collected using medical and nursing electronic records. Demographic data were: age, gender, weight, height, body mass index (BMI), COVID-19 status before procedure, comorbidity (Charlson Comorbidity Index, hypertension, diabetes, cardiovascular), length of ICU stay before tracheotomy (days), number of patients ventilated in an "easy" setting (PEEP $<12 \mathrm{mmHg}$ or an inspired fraction in $\mathrm{O}_{2}<0.6$ ) recommended in some guidelines as safe cut-off to practice tracheotomy [14]. Clinical and respiratory data before procedure were: preoperative SOFA score, Richmond Agitation sedation Score (RASS), PEEP, $\mathrm{FiO}_{2}$, $\mathrm{PaO}_{2} / \mathrm{FiO}_{2}$ ratio. Tracheotomy-related data were: length of surgical procedure in minutes, procedure-related complications (death, respiratory arrest, esophageal fistula, subcutaneous emphysema, pneumotorax or pneumomediastinum, major and minor bleeding, infection). The outcome data were the length of weaning from sedation (Richmond Agitation Sedation Score (RASS) score $0 \pm 1$ ) in days, patients weaned from mechanical ventilation and time required for a complete disconnection in days, subjects decannulated and length of tracheotomy stay in days, in-ICU and in-hospital mortality. All healthcare operators involved in these surgical procedures were tested for COVID-19 with pharyngeal swab and blood test (antibody test) to check their viral status after the intervention.

\section{Ethics}

All procedures performed in studies involving human participants were in accordance with the local ethical standards of the institution and with the 1964 Helsinki Declaration and its later amendments or comparable ethical standards.
All patients or their relatives in case of unconscious subjects were completely informed about risks and benefits related to the procedure. Written consent was given and collected for all procedures.

\section{Statistical analysis}

Numerical data were expressed as the median and interquartile range (IQR). Categorical variables were expressed in percentage. Our study is a unique not randomized cohort of patients, therefore statistical analysis is only descriptive. The statistic program used was Excel ${ }^{\mathrm{TM}}$ for Windows ${ }^{\mathrm{TM}}$.

\section{Results}

Among 68 cases of COVID-19 positive patients admitted to ICU in the period of study, we practiced 13 surgical tracheotomies (19.1\%) after a median period of invasive mechanical ventilation of 14 days (11-16 days, IQR). Other demographic data are summarized in Table 1.

At the moment of the procedure, $30.7 \%$ of patients were ventilated with a lower ventilator setting (PEEP $<12 \mathrm{mmHg}$ or $\left.\mathrm{FiO}_{2}<0.6\right)$. Clinical and respiratory data are summarized in Table 2.

Tracheotomy was realized within $20 \mathrm{~min}$ (15-20 min IQR). Postoperative complications observed during our study were pneumothorax in one case $(7.7 \%)$ and mild bleeding not requiring surgical revision in four cases $(30.7 \%)$. After surgical tracheotomy, patients were weaned from sedation in 3 days (3-20 days, IQR). During the period of our study, $53.8 \%$ of patients were completely weaned from mechanical ventilation within an average of 19 days (17-22 days) and $38.5 \%$ of patients were decannulated from 
Table 1 Demographic and preoperative data

Demographic and preoperative data

\begin{tabular}{ll}
\hline Age; median (IQR)-years & $60(56-65)$ \\
Gender & $85 \%$ male, 15\% female \\
Body mass index; median (IQR) & $29(28-35)$ \\
Charlson Comorbidity Index: median (IQR) & $2(2-3)$ \\
Comorbidity & \\
Hypertension & $61.5 \%$ \\
Diabetes & $23.1 \%$ \\
Cardiovascular & $30.8 \%$ \\
\hline
\end{tabular}

Demographic and preoperative comorbidity data of the patients submitted to tracheotomy are resumed in the table

$I Q R$ inter-quartile range

Table 2 Preoperative clinical and respiratory data

\begin{tabular}{lc}
\hline Preoperative clinical and respiratory data & Median, (IQR) \\
\hline SOFA score & $6(6$ to 9$)$ \\
Richmond Agitation Sedation Score (RASS) & $-5(-5$ to -4$)$ \\
PEEP ( $\mathrm{mmHg})$ & $10(10$ to 12$)$ \\
Fraction inspired in $\mathrm{O}_{2}\left(\mathrm{FiO}_{2}\right)$ & $0.45(0.4$ to 0.6$)$ \\
$\mathrm{PaO}_{2} / \mathrm{FiO}_{2}$ ratio & $152(122$ to 199$)$ \\
\hline
\end{tabular}

Average preoperative respiratory performance of the patients submitted to tracheotomy

PEEP positive end expiratory pressure

the surgical procedure (28-37 days, IQR) in post-ICU ward after 29 days.

In-ICU and in-hospital COVID-19 infection-related mortality were respectively of $23.1 \%$ and $30.7 \%$. There were no deaths due to tracheotomy complications. No healthcare operators were found positive for SARS-CoV2 by pharyngeal swab and blood test.

\section{Discussion}

\section{Tracheotomy during COVID-19 pandemic}

COVID-19 has recently spread all around the world in a quick and unpredictable way, overwhelming in a few days ICU capacity of most of the involved countries. COVID19 pneumonia, in some cases and in the most severe ones, required prolonged invasive mechanical ventilation due to severe respiratory failure ( $13 \%$ of hospitalized people) [3]. Although tracheotomy is commonly indicated to manage prolonged mechanical ventilation in standard critical care, its use is debated during the COVID-19 pandemic, counterbalancing positive points and risks related to the procedure. Tracheotomy enables to ease weaning from ventilator support, to facilitate airway suctioning clearing the patient's secretions, to improve his comfort and mobilization and eventually to prevent long-term complications (i.e. tracheal stenosis). On the other side, this procedure may present some risks for both patients and health care personnel in COVID-19 people. Tracheotomy is likely to worsen an already critically low hypoxia as frequently observed in these patients. Then this procedure could expose health care operators to contract viral infection due to high risk of viral spread [4].

\section{Indication for tracheotomy}

COVID-19 pandemic stressed the health care system around the world and Italy was one of the most hit countries. The presence of a great number of patients with severe respiratory failure requiring prolonged ICU recovery was the main reason to practice tracheotomy within few days. On the other hand, one of the most tricky points was about the prognosis of COVID-19 pneumonia due to the paucity of data from the literature. An early warning model for predicting mortality in viral pneumonia was introduced in a previous study but its validity in COVID-19 pneumonia is not confirmed [20]. Mortality rate in COVID-19 patients varies from different countries and studies. One previous work, made in the first period of the outbreak in China, showed that non-survivors were more likely to receive invasive mechanical ventilation (59\% vs. $15 \%$ ) and only $5.7 \%$ of ventilated patients survived after 28 days of ICU stay [21, 22]. In other studies, overall mortality rate reached $67 \%$ of all ICU patients [3] and over $50 \%$ in European work [11].

The decision for tracheotomy should involve a multidisciplinary discussion and should be supported by multiple team members. This process is quite complex and it must consider age, comorbidity, and ICU resources. In our experience, $19 \%$ of all ICU COVID-19 patients were prone to tracheotomy due to their young age and low comorbidity index. Our enrolled people were similar to other studies where patients presented a median age around 60 years old, more frequently male, obese (BMI > 29) and in good health status before COVID-19 [11, 14].

\section{Type and timing for tracheotomy}

We decided to practice surgical tracheotomy to reduce risks of aerosol generation and to guarantee more safety to patients (less disconnection, shorter apnea time, less reduction in positive airway pressure, and less risk of bleeding in these deep heparinized patients). Optimal timing for tracheotomy is still debated in COVID-19 patients [23, 24]. In fact, in such a complex and unpredictable situation, early tracheotomy may be futile while late tracheotomy is not likely to assist in ventilator weaning. During the early phase of 
COVID-19 pneumonia, tracheotomy was not recommended due to uncertain prognosis (within the first week), high viral load and the need for prone positioning, according to some authors [7]. On the other hand, the delay of the procedure could worsen the clinical course due to complications that occurred for prolonged tracheal intubation (tracheal stenosis, dysphagia) [6] and very high dosage of sedative required in such patients. Recently, it has been pointed out that prolonged intubation may pose a high risk of post-extubation dysphagia and subsequent increased risk of ab ingestis pneumonia, which may be detrimental in those patients who experience partial or prolonged lung recovery [6]. Although a role of early tracheotomy is not identified, it is possible that it may be beneficial, allowing a shorter intubation period, faster weaning and the possibility to protect the airways at the same time. A gap of 14-21 days from intubation is proposed in guidelines to allow sufficient decline in viral load [14]. In our experience, we practiced surgical tracheotomy within 14 days even if in a few cases prone positioning protocol went on. This gap was earlier than other experiences where tracheotomy was made in 20 days [21, 22], although other authors even reported an earlier timing [23]. The principal aims of our choice were to reduce deep sedation and to facilitate a complex and very long respiratory weaning. Our patients were weaned from sedation in a median period of 3 days and from mechanical ventilation within 19 days. This time for respiratory recovery was quite long, as expected, and similar to other experiences (18 days in a previous study on 270 mechanical ventilated patients) [16].

Guidelines and protocols recommended a 21 days delay to reduce viral load, but a clinical viral reduction may require many days and the choice to wait for a complete viral negativization could be clinically unfeasible as previously outlined [5]. In our experience, we decided to move up tracheotomy (within 14 days) to get easier management of such difficult patients.

\section{Ventilator setting}

In our study, a tracheotomy was practiced even if the patient was not ventilated in an easy manner (low PEEP and $\mathrm{FiO}_{2}$ ). Previous protocols and guidelines refer a PEEP level $<12 \mathrm{mmHg}$ and $\mathrm{FiO}_{2}<0.6$ as the clinical criteria for a safer elective tracheotomy [15].

COVID-19 pneumonia is characterized in most severe cases by a profound and prolonged reduction in oxygenation. In our experience, an easy ventilator setting was met in only $30 \%$ of enrolled cases. However, the need of a faster as possible weaning from sedation and neuromuscular blockage made us decide to practice surgical tracheotomy even if patients were still treated with higher PEEP and inspired oxygen.

\section{Safety of the procedure}

The surgical approach was considered the best choice in our experience when a negative pressure operating room and a skilled dedicated surgical team were available. The importance of a negative pressure operating room with air exchange implants has been underlined as the gold standard to minimize the viral spread and residual viral load in the surgical theatre, to achieve minimal risk for the healthcare workers. In this setting, less than $1 \%$ of the original viral load is present after 12 min from initial exposure [25]. The surgical approach allowed quick access to the airway with less manipulation and subsequent spread of SARS-CoV2 especially in subjects with higher BMI (BMI > 30), like some patients treated in our study. Furthermore, the bronchoscope required in the percutaneous approach may be a further aerosol-generating procedure with an increased infectious risk for personnel. The time to practice surgical or percutaneous tracheotomy was similar in our experience. In fact, median surgical time in our study (20 min, IQR 15-20 min) did not differ from time reported for the percutaneous approach in other experiences [16].

Mortality rate during a pandemic depends on the phase in which patients were enrolled, ICU capacity, and balance between the number of patients affected and ICU resources. Therefore, data about mortality derived from different studies are not comparable. In our experience, inICU and in-hospital mortality rate was respectively $23.1 \%$ and $30.7 \%$ lower than previous studies realized in the first phase of pandemic (67\%) [21]. Few complications were met in our experience. The most frequent post-procedural complications were minor bleeding (30.7\%) and pneumothorax (7.7\%). All COVID-19 positive patients received a full dose of heparin and this could explain why bleeding was the most common complication in such cases, although it was usually well controlled without surgical intervention. All health care personnel involved in tracheotomy remained COVID-19 negative to the pharyngeal swab and blood exams during this period of the pandemic.

\section{Limits}

The most important limitation of our study is related to the paucity of cases reported. Like other studies about this topic, our number of patients enrolled reflects the average flow of COVID-19 patients admitted in a single centre. Some authors encourage other centers to share their own experience with the aim to collect more robust and significant data [18]. 


\section{Conclusions}

In our experience surgical tracheotomy practiced following some important warning points about personnel equipment and technical variation is a safe tool in COVID-19 patients requiring prolonged invasive mechanical ventilation. This procedure is able to manage weaning from sedation and subsequently from prolonged and tricky mechanical ventilation. Ultimately, it is safe also for healthcare operators with an acceptable risk of viral spreading.

Acknowledgements A special thanks to all our colleagues, doctors, nurses, and healthcare operators who stayed in their own place during this fight against COVID-19 sharing fears, doubts, sadness but also enthusiasm and success. Lastly, a melancholy thought to our colleagues who escaped from their role overwhelmed by the fear of this invisible enemy.

\section{Funding None.}

\section{Compliance with ethical standards}

Conflict of interest The authors declare that they have no conflicts of interest.

Ethical approval The retrospective study was conducted in accordance with the ethical standards of the institutional and/or national research committee and with the 1964 Helsinki declaration and its later amendments or comparable ethical standards.

Informed consent All the patients had offered written informed consent.

\section{References}

1. World Health Organization (2020) WHO Director-General's opening remarks at the media briefing on COVID-19-March 112020. https://www.who.int/dg/speeches/detail/who-director-general-sopening-remarks-at-the-media-briefing-on-covid-19---11-march -2020. Accessed 20 May 2020

2. Piedmont Region-Civil Protection (2020) Regional report on COVID-19 outbreak. May 5 2020. https://www.regione.piemo nte.it/web/pinforma/notizie/coronavirus-gli-aggiornamenti-dalla -regione-piemonte. Accessed 20 May 2020

3. Phua J, Weng L, Ling L, Egi M, Lim CM, Divatia JV, Shrestha BR, Arabi YM, Ng J, Gomersall CD, Nishimura M, Koh Y, Du B (2020) Intensive care management of coronavirus disease 2019 (COVID-19): challenges and recommendations. Lancet Respir Med 8:506-517. https://doi.org/10.1016/S2213-2600(20)30161-2

4. McGrath BA, Ashby N, Birchall M, Dean P, Doherty C, Ferguson K, Gimblett J, Grocott M, Jacob T, Kerawala C, Macnaughton P, Magennis P, Moonesinghe R, Twose P, Wallace S, Higgs A (2020) Multidisciplinary guidance for safe tracheostomy care during the COVID-19 pandemic: the NHS National Patient Safety Improvement Programme (NatPatSIP). Anaesthesia 75:1659-1670. https ://doi.org/10.1111/anae.15120

5. Schultz MJ, Pattnaik R, Dondorp AM (2020) Walking the line between benefit and harm from tracheostomy in COVID-19. Lancet Respir Med 8:656-657. https://doi.org/10.1016/S2213 $-2600(20) 30231-9$
6. Lagier A, Melotte E, Poncelet M, Remacle S, Meunier P (2020) Swallowing function after severe COVID-19: early videofluoroscopic findings. Eur Arch Otorhinolaryngol 3:1-5. https://doi. org/10.1007/s00405-020-06522-6

7. McGrath BA, Brenner MJ, Warrillow SJ, Pandian V, Arora A, Cameron TS, Añon JM, Hernández Martínez G, Truog RD, Block SD, Lui GCY, McDonald C, Rassekh CH, Atkins J, Qiang L, Vergez S, Dulguerov P, Zenk J, Antonelli M, Pelosi P, Walsh BK, Ward E, Shang Y, Gasparini S, Donati A, Singer M, Openshaw PJM, Tolley N, Markel H, Feller-Kopman DJ (2020) Tracheostomy in the COVID-19 era: global and multidisciplinary guidance. Lancet Respir Med 8:717-725. https://doi.org/10.1016/S2213 $-2600(20) 30230-7$

8. Schultz P, Morvan JB, Fakhry N, Morinière S, Vergez S, Lacroix C, Bartier S, Barry B, Babin E, Couloigner V, Atallah I (2020) French consensus regarding precautions during tracheostomy and post-tracheostomy care in the context of COVID-19 pandemic. Eur Ann Otorhinolaryngol Head Neck dis 137:167-169. https:// doi.org/10.1016/j.anorl.2020.04.006

9. Sommer DD, Engels PT, Weitzel EK, Khalili S, Corsten M, Tewfik MA, Fung K, Cote D, Gupta M, Sne N, Brown TFE, Paul J, Kost KM, Witterick IJ (2020) Recommendations from the CSO-HNS task-force on performance of tracheotomy during the COVID-19 pandemic. J Otolaryngol Head Neck Surg 49:23. https ://doi.org/10.1186/s40463-020-00414-9

10. Chao TN, Braslow BM, Martin ND, Chalian AA, Atkins J, Haas AR, Rassekh CH (2020) Tracheotomy in ventilated patients with COVID-19. Guidelines from the COVID-19 Tracheotomy Task Force, a Working Group of the Airway Safety Committee of the University of Pennsylvania Health System Tracheotomy in Ventilated Patients With COVID-19. Ann Surg 272:e30-e32. https:// doi.org/10.1097/SLA.0000000000003956

11. Takhar A, Walker A, Tricklebank S, Wyncoll D, Hart N, Jacob T, Arora A, Skilbeck C, Simo R, Surda P (2020) Recommendation of a practical guideline for safe tracheostomy during the COVID 19 pandemic. Eur Arch Otorhinolaryngol 277:2173-2184. https ://doi.org/10.1007/s00405-020-05993

12. Pichi B, Mazzola F, Bonsembiante A, Petruzzi G, Zocchi J, Moretto S, De Virgilio A, Pellini R (2020) CORONA-steps for tracheotomy in COVID-19 patients: a staff-safe method for airway management. Oral Oncol 105:104682. https://doi.org/10.1016/j. oraloncology.2020.104682

13. Zhang X, Huang Q, Niu X, Zhou T, Xie Z, Zhong Y, Xiao H (2020) Safe and effective management of tracheostomy in COVID-19 patients. Head Neck 42:1374-1381. https://doi. org/10.1002/hed.26261

14. David AP, Russell MD, El-Sayed IH, Russell MS (2020) Tracheostomy guidelines developed at a large academic medical center during the COVID-19 pandemic. Head Neck 42:1291-1296. https ://doi.org/10.1002/hed.26191

15. Heyd CP, Desiato VM, Nguyen SA, O'Rourke AK, Clemmens CS, Awad MI, Worley ML, Day TA (2020) Tracheostomy protocols during COVID-19 pandemic. Head Neck 42:1297-1302. https:// doi.org/10.1002/hed.26192

16. Turri-Zanoni M, Battaglia P, Czaczkes C, Pelosi P, Castelnuovo P, Cabrini L (2020) Elective tracheostomy during mechanical ventilation in patients affected by COVID-19: preliminary case series from Lombardy, Italy. Otolaryngol Head Neck Surg 163:135-137. https://doi.org/10.1177/0194599820928963

17. Angel L, Kon ZN, Chang SH, Rafeq S, Palasamudram Shekar S, Mitzman B, Amoroso N, Goldenberg R, Sureau K, Smith DE, Cerfolio RJ (2020) Novel percutaneous tracheostomy for critically Ill patients with COVID-19. Ann Thorac Surg 110:1006-1011. https://doi.org/10.1016/j.athoracsur.2020.04.010

18. Mattioli F, Fermi M, Ghirelli M, Molteni G, Sgarbi N, Bertellini E, Girardis M, Presutti L, Marudi A (2020) Tracheostomy in 
the COVID 19 pandemic. Eur Arch Otorhinolaryngol 277:21332135. https://doi.org/10.1007/s00405-020-05982-0

19. Piccin O, Albertini R, Caliceti U, Cavicchi O, Cioccoloni E, Demattè M, Ferri GG, Macrì G, Marrè P, Pelligra I, Saggese D, Schiavon P, Sciarretta V, Sorrenti G (2020) Early experience in tracheostomy and tracheostomy tube management in Covid-19 patients. Am J Otolaryngol 41:102535. https://doi.org/10.1016/j. amjoto.2020.102535

20. World Health Organization (2020) Rational use of personal protective equipment for coronavirus disease (COVID-19): interim guidance. February 272020 WHO/2019-nCov/IPC PPE_use/2020.1. https://apps.who.int/iris/handle/10665/331215. Accessed 25 May 2020

21. Chen N, Zhou M, Dong X, Qu J, Gong F, Han Y, Qiu Y, Wang J, Liu Y, Wei Y, Xia J, Yu T, Zhang X, Zhang L (2020) Epidemiological and clinical characteristics of 99 cases of 2019 novel coronavirus pneumonia in Wuhan, China: a descriptive study. Lancet 395:507-513. https://doi.org/10.1016/S0140-6736(20)30211-7

22. Yang X, Yu Y, Xu J, Shu H, Xia J, Liu H, Wu Y, Zhang L, Yu Z, Fang M, Yu T, Wang Y, Pan S, Zou X, Yuan S, Shang Y (2020) Clinical course and outcomes of critically ill patients with SARSCoV-2 pneumonia in Wuhan, China: a single-centered, retrospective, observational study. Lancet Respir Med 8:465-481. https:// doi.org/10.1016/S2213-2600(20)30079-5
23. Martin-Villares C, Perez Molina-Ramirez C, Bartolome-Benito M, Bernal-Sprekelsen M, COVID ORL ESP Collaborative Group (2020) Outcome of 1890 tracheostomies for critical COVID-19 patients: a national cohort study in Spain. Eur Arch Otorhinolaryngol 4:1-8. https://doi.org/10.1007/s00405-020-06220-3

24. Ferri E, Boscolo Nata F, Pedruzzi B, Campolieti G, Scotto di Clemente F, Baratto F, Cristalli G (2020) Indications and timing for tracheostomy in patients with SARS CoV2-related. Eur Arch Otorhinolaryngol 277:2403-2404. https://doi.org/10.1007/s0040 5-020-06068-7

25. Rovira A, Dawson D, Walker A, Tornari C, Dinham A, Foden N, Surda P, Archer S, Lonsdale D, Ball J, Ofo E, Karagama Y, Odutoye T, Little S, Simo R, Arora A (2020) Tracheostomy care and decannulation during the COVID-19 pandemic. A multidisciplinary clinical practice guideline. Eur Arch Otorhinolaryngol 17:1-9. https://doi.org/10.1007/s00405-020-06126-0

Publisher's Note Springer Nature remains neutral with regard to jurisdictional claims in published maps and institutional affiliations. 